\title{
Psychophysiological Stress Response of Novice Cavers in a Speleology Route
}

\author{
José Francisco Tornero-Aguilera, $\mathrm{PhD}^{1,2}$; Joaquín Sanchez-Molina, $\mathrm{PhD}^{2}$; \\ Valentín E. Fernández-Elías, $\mathrm{PhD}^{2}$; Vicente Javier Clemente-Suárez, $\mathrm{PhD}^{1,2,3}$ \\ ${ }^{1}$ Research Center in Applied Combat (CESCA), Toledo, Spain; ${ }^{2}$ Faculty of Sports Science, Universidad Europea de Madrid, Madrid, Spain; ${ }^{3}$ Grupo de \\ Investigación en Cultura, Educación y Sociedad, Universidad de la Costa, Barranquilla, Colombia
}

\begin{abstract}
Introduction-Speleology/Caving is a recreational outdoor activity that has drawn an increasing number of participants in recent years, but there is little information on the physiological and psychological demands of this outdoor activity. This research aimed to analyze the psychophysiological response of novice cavers to a caving route.

Methods-Modifications in autonomic modulation, ratings of perceived exertion, and perceived stress were evaluated in physically active participants before, during, and after a caving route of 3-h duration.

Results-Eighteen participants were assessed. We found an anticipatory anxiety response in the participants before starting the route and significant increases in the ratings of perceived exertion, stress perception, autonomous sympathetic modulation as evaluated by heart rate variability while on the route, and sympathetic modulation $30 \mathrm{~min}$ after finishing the caving route.

Conclusions - A speleology route produced an anticipatory anxiety response, an increase in the sympathetic stress response, fatigue symptoms at the autonomic nervous system level, and low perception of stress and effort compared with the autonomic stress response. This information could help to better prepare participants for this demanding event, potentially avoiding accidents and injuries and increasing safety for cavers.
\end{abstract}

Keywords: heart rate variability, autonomic modulation, accident, stress, outdoor activities

\section{Introduction}

There is increasing interest in using the natural environment to perform physical exercise for leisure, health, recreational, or competitive reasons. ${ }^{1}$ Speleology, also known as caving, is the exploration of natural underground caves, an increasingly popular recreational activity. ${ }^{2}$ Caving may range from simple guided walks to complex and challenging endeavors over several hours, weeks, or even months in a demanding and stressful environment, potentially requiring long hours of walking, climbing, crawling, and/or ropework in muddy, dark, wet, and slippery

Corresponding author: Vicente Javier Clemente Suárez, PhD, Vicente J. Clemente, Facultad de Ciencias de la actividad física y el deporte, Universidad Europea, Calle Tajo s/n. Madrid; e-mail: vctxente@yahoo.es. Submitted for publication September 2019.

Accepted for publication February 2020. conditions. Sometimes these activities may be performed without electric communication owing to the convoluted terrain. ${ }^{3}$

The challenging environment of caving combines darkness and claustrophobic spaces with some similarity to those found in some military contexts, such as underground, close-quarter, or air combat. Caving may produce an increased anxiogenic response that negatively affects different abilities such as attentional focus, information processing, working memory, and consciousness of time, like those experienced in military combat, ${ }^{4-6}$ and claustrophobia episodes. ${ }^{7}$ These capacities are controlled by the amygdala, striatum, cerebellum, prefrontal cortex, and hippocampus cortical regions, ${ }^{8}$ structures sensitive to high-stress situations in which decision-making processes such as the capacity to retain and manipulate information can be altered. ${ }^{9}$ These factors could compromise cavers' physical integrity, considering incidents often demand timely response. Epidemiologic studies of caving injuries 


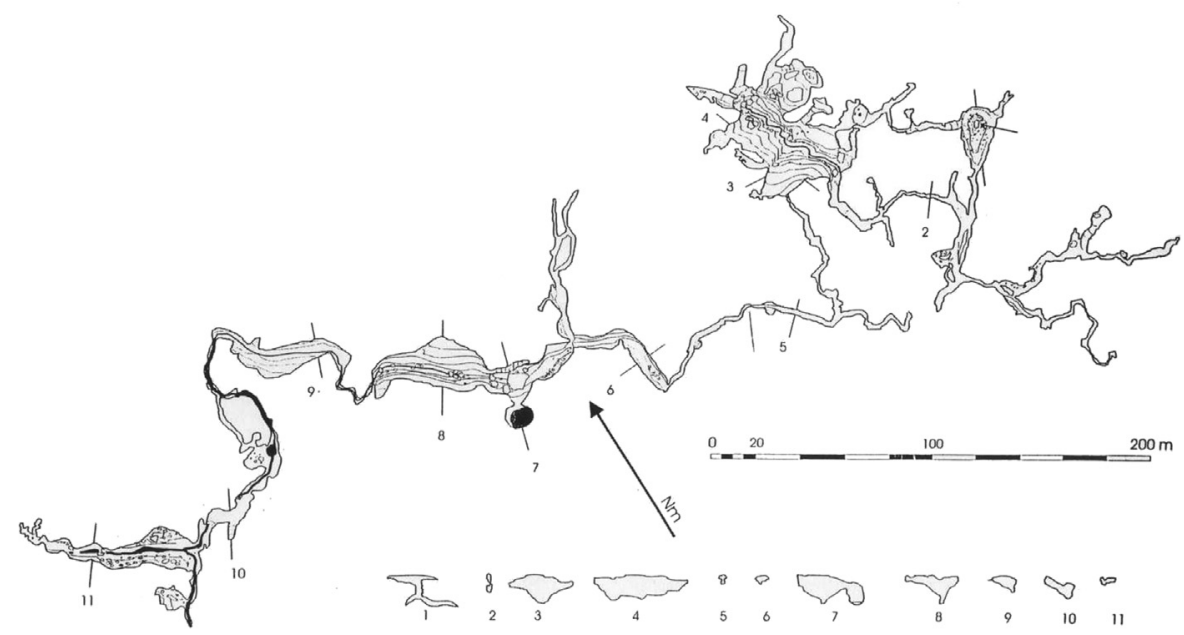

Figure 1. Map of the cave.

from the United States describe a total of 1356 victims, 74\% as a result of traumatic events, some of which might have been avoided with greater preparation and environmental awareness. $^{2}$

Exposure to stressful environments, such as caves, ${ }^{8}$ produces an alteration in the autonomic modulation stemming from the activation of the phylogenetic "fight-or-flight" system, which increases sympathetic modulation that may also affect physical and psychological integrity. ${ }^{10}$ In this environment, the demanding context of a speleology route (high humidity and long hours of walking, crawling, climbing, ropework, and sometimes immersion in water) could lead to dehydration and possibly hyperthermia, which would significantly impair aerobic and exercise performance. ${ }^{11}$ However, little is known about the physiologic and psychological response of practitioners in this environment. We conducted the present research to analyze the psychophysiological response of novice participants completing a speleology route. We hypothesized that the speleology route would produce an increase in sympathetic autonomic modulation.

\section{Methods}

\section{SPELEOLOGY ROUTE DESCRIPTION}

In both the preceding days and immediately before entering the cave, participants were informed about the techniques and maneuvers that they had to perform during the route. Afterward, the participants entered the cave through an entrance chasm about $10 \mathrm{~m}$ deep. Vertical progression material was required (harness, ropes, and abseiling staff). They would emerge through that same well, using vertical efforts and climbing equipment. The cavern extended about $1500 \mathrm{~m}$ in length underground (Figure 1). All participants had a map of the cave, and they set up turns to lead the group. This action ensured the participants paid attention to where they were at every moment and where they were going and cared for their colleagues.

After descending the entrance hole, participants met in groups of 10 and progressed together with the speleologist guide. They proceeded south until the first junction. From there, they went to the right through pass 2 to room 3 , which was very wide and had many geological formations. Once they identified where they were, they moved toward tube 5 and proceeded to a few larger rooms, 6 to 9 , from which it was no longer possible to continue. During their progression, participants passed through several narrow points (Figure 2) where they not only had to crawl and creep but also had to adapt the position of the whole body and head to the arrangement of the rocks' geomorphology. They then moved toward the eastern galleries, and from there to passage 5. After arriving at the end of the cave, participants had to retrace their path.

\section{PROCEDURE}

We assessed the autonomic modulation of participants through heart rate variability (HRV) analysis using Polar Team Pro equipment (Polar, Kempele, Finland) following previously reported research protocols. ${ }^{12,13}$ This evaluation allowed us to objectively determine sympathetic and parasympathetic activation in a noninvasive, easily accessible, and affordable way. The intervals between successive heartbeats (RR intervals) were analyzed by the Kubios HRV software (version 2.0, Biosignal Analysis and Medical Imaging Group, University of Kuopio, Finland). Previous research found different sensitivity depending on the HRV domain and the characteristics of the context. ${ }^{14-16}$ We analyzed 2 HRV domains to discern modification in HRV in this particular context. 


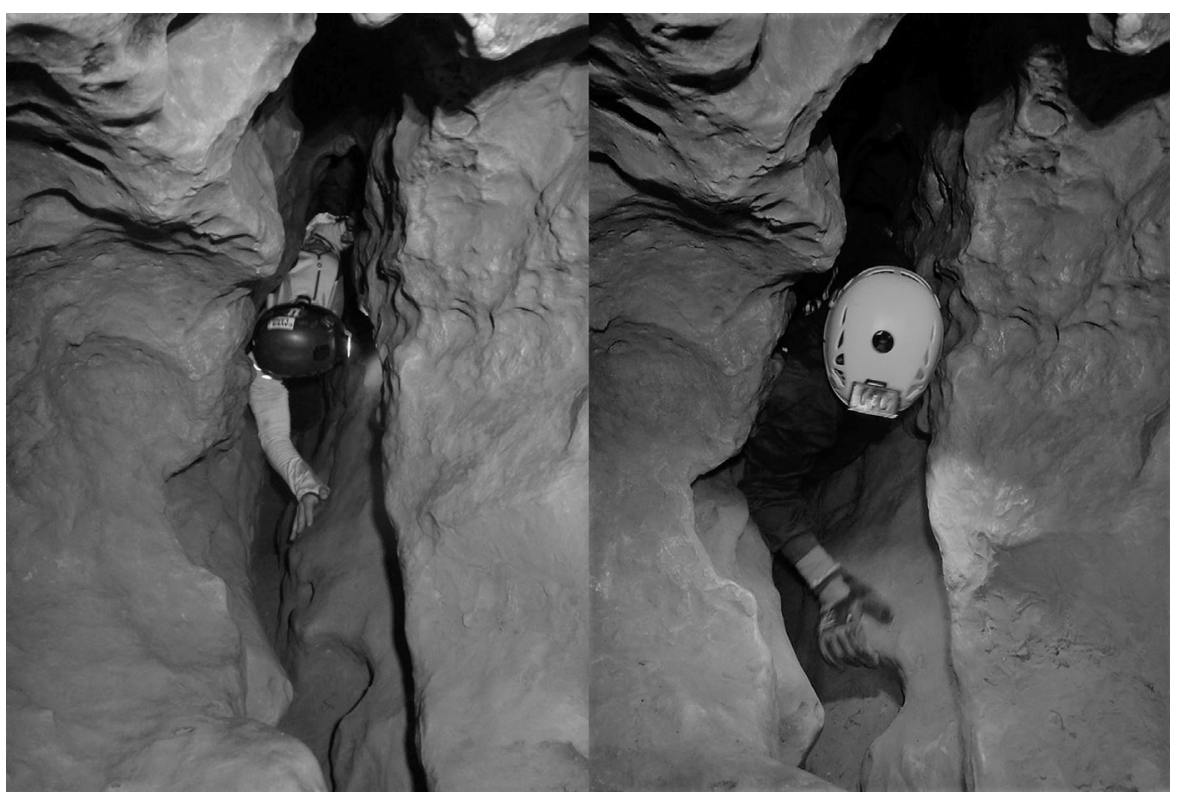

Figure 2. Participant crawling.

Time-domain (nonspectral) analysis was based on the assessment of the intervals between normal heartbeats. During statistical analysis, generally all of the QRS complexes, the duration between consecutive QRS complexes (normal to normal $[\mathrm{NN}]$ interval), or the instantaneous heart rates during continuous electrocardiogram recordings are determined. We recorded the following time-domain indices as follows: RMSSD (ms), square root of the mean value of the sum of squared differences of all successive R-R intervals; and SDNN (ms), the standard deviation of the interbeat interval from which artifacts were removed (NN).

Frequency-domain/spectral measures (spectral) analysis provides information on how power is distributed as a function of frequency. This provides smoother spectral components that can be distinguished as independent from preselected frequency bands and allows easy postprocessing of the spectrum with an automatic calculation of lowand high-frequency power components, easy identification of the central frequency of each component, and an accurate estimation even on a small number of samples. ${ }^{16}$ High frequency (HF) and low frequency (LF) (normal units) were measured to analyze the peaks of parasympathetic HF component (frequency range: $0.15-0.40 \mathrm{~Hz}$ ) and sympathetic LF component frequency range $(0.04-0.15 \mathrm{~Hz})$ values.

HRV measurement was performed in 5 key moments of the activity, as follows:

- Thirty minutes before entering the cave. This period included a small walk of $400 \mathrm{~m}$ and the pre-entry briefing. The explanations were given close to the entrance (M0).
- Participants remained inside the cave for $3 \mathrm{~h}$, including the abseiling and the lifting-out maneuvers. To check the variations in their anxiogenic response, 3 periods of $1 \mathrm{~h}$ were measured: an interval corresponding to the first third of the speleology route (M1), an interval corresponding to the second third of the speleology route (M2), and an interval corresponding to the last third of the speleology route (M3).

- Once out of the cave, a period of over 30 min was measured. This interval included a small resting time around the cave and walking back to the bus (M4).

Before and immediately after the finalization of the route, subjective perception of distress was assessed using scales of subjective units of distress (SUDS) and rating of perceived exertion (RPE). When participants are familiarized with both scales, they provide well-validated information related to the psychological state of perceived stress. ${ }^{17}$ The SUDS scores range from 0 to $100,{ }^{14}$ representing the level of distress perceived by the participant at the time of evaluation, with 0 meaning "completely indifferent and cold; does not affect me" and 100 being "so distressed and tense that I can't deal with it." This scale was applied $5 \mathrm{~min}$ before the start of the speleology route and provided information on the level of stress as assessed by the individual, representing the cognitive relationship between the objective event and the emotional response. ${ }^{15,16}$ The RPE scale ranged from 6 ("no effort") to 20 ("maximal effort"). This scale provides information about the individual's perception of physiologic effort in physical activities. ${ }^{18}$ 


\section{STATISTICAL ANALYSIS}

Data are presented as mean \pm SD. The Shapiro-Wilk test was used to confirm normal distribution of data. Heart raterelated variables were analyzed using a 1-way analysis of variance (ANOVA) with repeated measures. After a significant $\mathrm{F}$ ratio was obtained (Greenhouse-Geisser adjustment for sphericity), pairwise differences were identified using Tukey's (honest significant difference) post hoc procedure. RPE and SUDS data were analyzed by Student's t test with repeated measures. The level of significance was set at $P<0.05$. Data analysis was performed using SPSS software v. 21 (IBM, Chicago, IL).

\section{Results}

Eighteen physically active participants $(22.5 \pm 1.9 \mathrm{y}, 71.3 \pm$ $11.9 \mathrm{~kg}, 174 \pm 9 \mathrm{~cm}, 23.4 \pm 3.3 \mathrm{~kg} \cdot \mathrm{m}^{-2}$ body mass index) with no previous experience in caving volunteered for this study and were analyzed. All the procedures were conducted following the Helsinki Declaration (as revised in Brazil, 2013) and approved by the European University of Madrid research ethics committee (CIPI/18/074). The data were collected anonymously. Prior to participation, all volunteers were informed about the experimental procedures and given the right to withdraw from the study at any time. Each provided written informed consent.

The RPE of participants increased $3.5 \pm 2.7$ points after

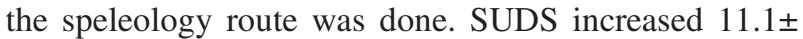
15.8 units after caving. Both increments were significantly different $(P<0.05$; Figure 3$)$. Regarding HRV data (Table 1), $\mathrm{HR}_{\text {mean }}$ significantly increased at M2, M3, and POST compare to PRE and M1 $(P<0.05)$. HR $\mathrm{Hin}_{\text {in }}$ was significantly higher at POST compare to PRE $(P<0.05)$ and at M2, M3, and POST compared to M1 $(P<0.05)$. $\mathrm{HR}_{\max }$ was significantly increased at M2, M3, and POST compared to PRE $(P<0.05)$. LF outcomes were significantly higher at M2 and M3 compared to PRE $(P<0.05)$. RMSSD was significantly lower at M2, M3, and POST compared to PRE $(P<0.05)$. SDNN was significantly lower at POST compared to PRE and at M2, M3, and POST compare to M1 $(P<0.05)$. No significant differences were found in $\mathrm{HF}$ and $\mathrm{LF} / \mathrm{HF}$ ratios. $\mathrm{F}$ and $P$ values of the ANOVA performed for HRV variable comparisons are shown in Table 1.

\section{Discussion}

This research aimed to analyze the psychophysiological response of inexperienced participants in a speleology route. We hypothesized that the speleology route would produce a significant increase in the sympathetic autonomic modulation of participants.
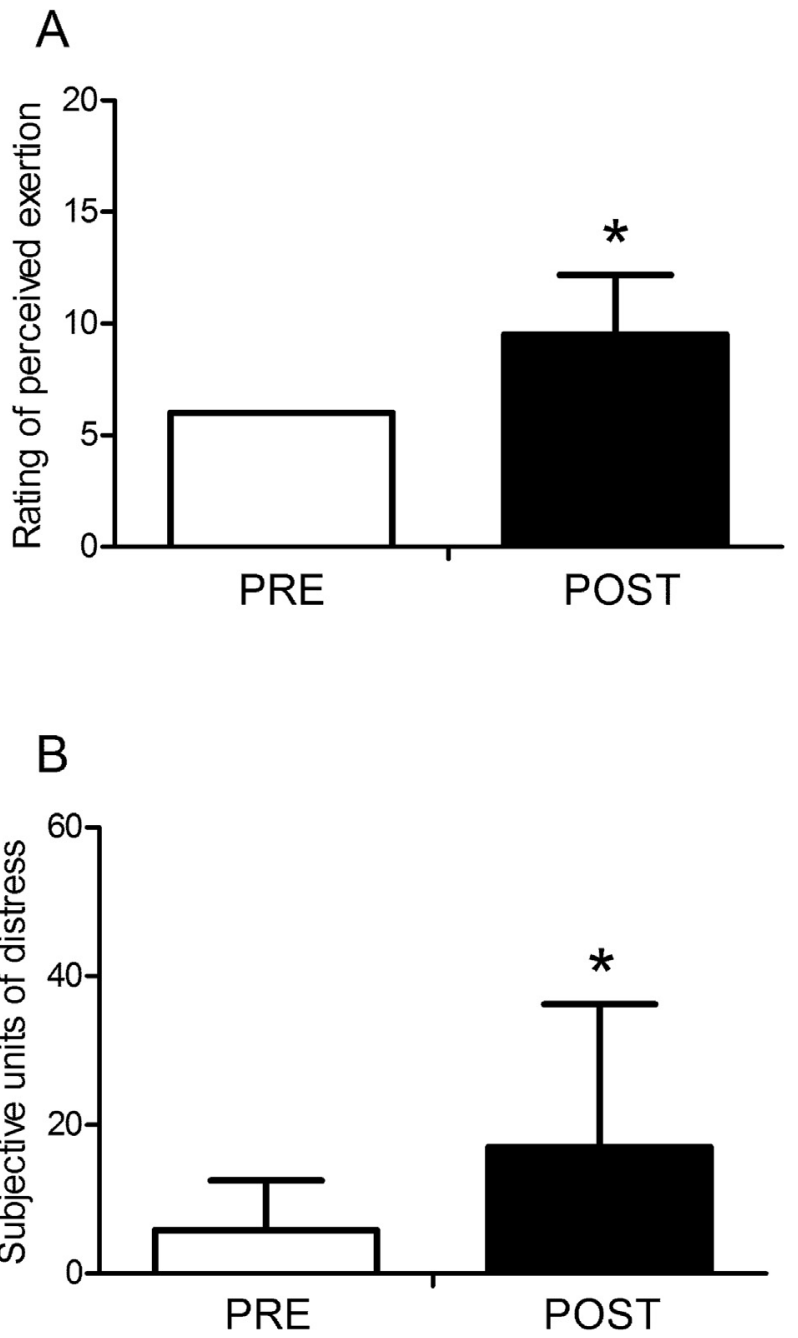

Figure 3. A. Rating of perceived exertion before and after completing the speleology route. B. Subjective units of distress before and after completing the speleology route. Data for both panels are mean \pm SD. *Significantly different from PRE $(P<0.05)$.

To our knowledge, no previous studies had examined the autonomic anxiogenic response in real caving activities. Most leading caving experts and researchers focused on medical aspects, such as caving incidents, injuries, and epidemiology - not surprising, considering the medical and logistical challenges that are associated with cave rescue operations. ${ }^{19,20}$ Only some studies have addressed cavers' physiologic demands with regard to extreme heat and humidity conditions, ${ }^{21}$ biochemical modifications, ${ }^{22}$ hematologic changes ${ }^{23}$ body composition, hydration level, ${ }^{3}$ and energy expenditure. ${ }^{24}$ This lack of knowledge about the organic response in this context potentially increases the risks faced by participants.

Given that the demanding context of the cave limited the movement of participants (narrow, with long corridors no 
Table 1. Heart rate variability data before (PRE), at $1 \mathrm{~h}(\mathrm{M} 1)$, at $2 \mathrm{~h}(\mathrm{M} 2)$, at $3 \mathrm{~h}$ (M3), and after (POST) speleology route

\begin{tabular}{|c|c|c|c|c|c|c|c|c|}
\hline Variable & $P R E$ & $M 1$ & M2 & M3 & POST & $F$ & $P$ & Intermoment comparison \\
\hline $\begin{array}{l}\mathrm{HR}_{\text {mean }} \\
\quad \text { (beats } \cdot \min ^{-1} \text { ) }\end{array}$ & $84 \pm 10$ & $88 \pm 11$ & $103 \pm 14$ & $104 \pm 17$ & $108 \pm 17$ & 24.78 & $<0.0001$ & $\begin{array}{l}\mathrm{PRE}<\mathrm{M} 2 ; \mathrm{PRE}<\mathrm{M} 3 ; \\
\mathrm{PRE}<\mathrm{POST} ; \mathrm{M} 1<\mathrm{M} 2 ; \\
\mathrm{M} 1<\mathrm{M} 3 ; \mathrm{M} 1<\mathrm{POST}\end{array}$ \\
\hline $\begin{array}{l}\mathrm{HR}_{\text {min }} \\
\quad \text { (beats } \cdot \min ^{-1} \text { ) }\end{array}$ & $61 \pm 9$ & $56 \pm 14$ & $68 \pm 9$ & $70 \pm 13$ & $71 \pm 17$ & 6.45 & 0.0002 & $\begin{array}{l}\mathrm{PRE}<\mathrm{POST} ; \mathrm{M} 1<\mathrm{M} 2 ; \\
\mathrm{M} 1<\mathrm{M} 3 ; \mathrm{M} 1<\mathrm{POST}\end{array}$ \\
\hline $\begin{array}{l}\mathrm{HR}_{\max } \\
\quad \text { (beats } \cdot \min ^{-1} \text { ) }\end{array}$ & $128 \pm 23$ & $143 \pm 21$ & $150 \pm 18$ & $154 \pm 19$ & $151 . \pm 21$ & 6.03 & 0.0003 & $\begin{array}{l}\mathrm{PRE}<\mathrm{M} 2 ; \mathrm{PRE}<\mathrm{M} 3 ; \\
\mathrm{PRE}<\mathrm{POST}\end{array}$ \\
\hline $\mathrm{LF}(\mathrm{nu})$ & $70.7 \pm 9.7$ & $74.7 \pm 8.5$ & $79.8 \pm 5.3$ & $80.3 \pm 8.0$ & $74.3 \pm 13.2$ & 4.06 & 0.0052 & $\mathrm{PRE}<\mathrm{M} 2 ; \mathrm{PRE}<\mathrm{M} 3$ \\
\hline $\mathrm{HF}(\mathrm{nu})$ & $29.2 \pm 9.7$ & $30.1 \pm 18.9$ & $20.1 \pm 5.3$ & $23.1 \pm 14.0$ & $25.5 \pm 13.0$ & 2.22 & 0.0757 & - \\
\hline LF/HF (nu) & $3.0 \pm 2.2$ & $3.5 \pm 2.0$ & $4.5 \pm 2.1$ & $5.1 \pm 3.1$ & $4.0 \pm 2.6$ & 2.21 & 0.0766 & - \\
\hline RMSSD (ms) & $57.2 \pm 21.9$ & $50.6 \pm 17.8$ & $39.4 \pm 22.6$ & $34.7 \pm 16.9$ & $35.6 \pm 24.6$ & 5.78 & 0.0005 & $\begin{array}{l}\text { PRE }>M 2 ; \text { PRE }>M 3 \\
\text { PRE }>\text { POST }\end{array}$ \\
\hline SDNN (ms) & $120.6 \pm 36.8$ & $144.5 \pm 38.1$ & $103.2 \pm 33.2$ & $102.4 \pm 27.1$ & $84.5 \pm 44.7$ & 9.89 & $<0.0001$ & $\begin{array}{l}\text { PRE>POST; M1>M2; } \\
\text { M1>M3; M1>POST }\end{array}$ \\
\hline
\end{tabular}

Data presented are mean \pm SD.

$\mathrm{HF}$, high frequency; $\mathrm{HR}_{\max }$, maximum heart rate; $\mathrm{HR}_{\text {mean }}$, mean heart rate; $\mathrm{HR}_{\min }$, minimum heart rate; $\mathrm{LF}$, low frequency; $\mathrm{LF} / \mathrm{HF}$, low frequency and high frequency ratio; nu, normal units; RMSSD, root mean square of the successive differences of the RR intervals; SDNN, standard deviation of R-R intervals.

more than $1.5 \mathrm{~m}$ high by $0.8 \mathrm{~m}$ wide), we expected a low cardiovascular response associated with these movements performed at low speed. Nevertheless, the heart rate of participants significantly increased, probably not principally due to the physical demands but rather the psychological stress response induced by them. ${ }^{17}$ The overstimulation produced by these situations, in which risk to physical integrity and life is perceived, produced an anxiogenic response and an increased sympathetic response that led to an increase in cardiovascular response. ${ }^{5}$

The increase in sympathetic modulation was reflected in the decreased RMSSD and SDNN. ${ }^{25}$ This response was not only evaluated during the caving activity. Before entering the cave, participants presented high sympathetic activity that was maintained during the activity, as high LF (sympathetic HRV frequency domain parameter) values showed. This anxiety anticipatory response was also evaluated in other high-demand situations, such as ultraendurance events, clinical stays, examinations, and military maneuvers. ${ }^{15,26,27}$ This response showed that when participants only thought of the uncertainty and demands of the task, they experienced a high sympathetic response that prepared their organic systems to face possible threats that may arise. The strong autonomic stress response has a direct effect on different cortical structures that can negatively affect decision making and different aspects of memory. This phenomenon can lead to bad decisions or actions that may endanger individual or group physical integrity, as previous authors showed in other contexts 5,28 and as has been seen specifically in caves recently. ${ }^{29}$

In addition, during the caving exploration, sympathetic activity tends to increase: A significant increase in LF and decrease in HF and RMSSD from M1 to M2 and M3 was found. These increases in sympathetic activity reflect the impact of fatigue on the autonomous response of participants, which compounds the previous sympathetic overstimulation due to the stressful context of the cave. ${ }^{30}$ The continuous physical effort and technical demands could be the main causes that accentuated sympathetic hyperactivity showing those symptoms of fatigue. In addition, sympathetic nervous system activation was still found after completion of the speleology route; the LF and HF/LF ratio remained significantly higher than in the basal state, and significantly lower values were found for RMSSD and HF. This maintained sympathetic modulation postactivity was also found in paratroopers after parachute jumps and shows the elevated activation that these highrisk activities entail. These are factors to take into account when programming these activities. ${ }^{31}$

The anxiogenic response evaluated in the caving route produced a significant increase in the subjective perception of exertion and stress, but values reached in these parameters were lower than in other stressful activities, such as sports events. ${ }^{32,33}$ This misinterpretation of response was also found in stressful environments, such as military combat, ${ }^{34}$ and could be due to the negative effect of increased sympathetic activation in cortical structures such as the hippocampus and brain areas related to the processing of information. ${ }^{12}$

\section{PRACTICAL APPLICATIONS}

The anticipatory anxiety response and the increased sympathetic response caused by the speleology route showed the 
large impact of this activity on the participants. Nevertheless, participants reported low levels of perceived stress and effort. This combination could lead them to continue their route beyond their real capacity, leading to a continued hyperactivated sympathetic physiologic state in which information processing, consciousness of time, and decision making would be negatively affected,,$^{5,6,35-37}$ thus increasing risk in this challenging environment.

\section{LIMITATIONS}

Perceived distress and physical exertion may have been affected by participants' recall of previous stressful situations experienced, similar or not to the speleology route. In addition, the data and conclusions of the present study should be considered specifically for this cave because we did not compare our participants to expert cavers or this cave to other types of caves. Consequently, another limitation of this study is the small number of participants and the absence of hormonal stress response analysis and monitoring of alpha-amylase and cortisol.

\section{Conclusions}

A speleology route produced an anticipatory anxiety response, an increase in the sympathetic stress response, fatigue symptoms at the autonomic nervous system level, and a low perception of stress and effort. This information could help better prepare participants in this demanding event, avoiding accidents and injuries and increasing the safety of cavers.

Acknowledgments: We acknowledge the participants for their invaluable contributions to the study.

Author Contributions: conceptualization, methodology (VJC-S, JFTA); software (VJC-S); validation (VJC-S, VEFE); formal analysis (VJC-S, JSM); investigation (VJC-S, JSM); resources (VJC-S, JFTA); data curation (VJC-S); writing — original draft preparation (VJC-S, VEFE); writing - review and editing (VJC-S, JSM); visualization (VJC-S, VEFE); supervision (VJC-S, JFTA); project administration (VJC-S).

Financial/Material Support: The present research was developed with the David A. Wilson award for excellence in teaching and learning research award 2017, project number XOTRIO1712.

Disclosures: None.

\section{References}

1. Palmberg IE, Kuru J. Outdoor activities as a basis for environmental responsibility. J Environ Educ. 2000;31(4): 32-6.

2. Stella-Watts AC, Holstege CP, Lee JK, Charlton NP. The epidemiology of caving injuries in the United States. Wilderness Environ Med. 2012;23(3):215-22.

3. Antoni G, Marini E, Curreli N, Tuveri V, Comandini O, Cabras S, et al. Energy expenditure in caving. PloS One. 2017;12(2), e0170853.
4. Tornero-Aguilera JF, Robles-Pérez JJ, Clemente-Suárez VJ. Use of psychophysiological portable devices to analyse stress response in different experienced soldiers. J Med Syst. 2018;42(4):75.

5. Tornero-Aguilera JF, Clemente-Suarez VJ. Effect of experience, equipment and fire actions in psychophysiological response and memory of soldiers in actual underground operations. Int J Psychophysiol. 2018;128:40-6.

6. Delgado-Moreno R, Robles-Pérez JJ, Clemente-Suárez VJ. Combat stress decreases memory of warfighters in action. J Med Syst. 2017;41(8):124.

7. Lambrou P, Pratt G, Chevalier G. Physiological and psychological effects of a mind/body therapy on claustrophobia. Subtle Energies Energy Med. 2003;14(3):239-51.

8. Cabeza R, Daselaar SM, Dolcos F, Prince SE, Budde M, Nyberg L. Task-independent and task-specific age effects on brain activity during working memory, visual attention and episodic retrieval. Cereb Cortex. 2004;14(4):364-75.

9. Tornero-Aguilera JF, Robles-Pérez JJ, Clemente-Suárez VJ. Effect of combat stress in the psychophysiological response of elite and non-elite soldiers. J Med Syst. 2017;41(6):100.

10. Hormeño-Holgado AJ, Perez-Martinez MA, ClementeSuárez VJ. Psychophysiological response of air mobile protection teams in an air accident manoeuvre. Physiol Behav. 2019;199:79-83.

11. Sawka MN. Physiological consequences of hypohydration: exercise performance and thermoregulation. Med Sci Sports Exerc. 1992;24(6):657-70.

12. Delgado-Moreno R, Robles-Pérez JJ, Aznar-Laín S, Clemente-Suárez VJ. Effect of experience and psychophysiological modification by combat stress in soldier's memory. J Med Syst. 2019;43(6):150.

13. Belinchon-deMiguel P, Clemente-Suárez VJ. Psychophysiological, body composition, biomechanical and autonomic modulation analysis procedures in an ultraendurance mountain race. J Med Syst. 2018;42(2):32.

14. Clemente-Suárez VJ, Beltrán-Velasco AI, Bellido-Esteban A, Ruisoto-Palomera P. Autonomic adaption to clinical simulation in psychology students: teaching applications. Appl Psychophysiol Biofeedback. 2018;43(3):239-45.

15. Beltrán-Velasco AI, Bellido-Esteban A, RuisotoPalomera P, Clemente-Suárez VJ. Use of portable digital devices to analyze autonomic stress response in psychology objective structured clinical examination. J Med Syst. 2018;42(2):35.

16. Sánchez-Conde P, Beltrán-Velasco AI, Clemente-Suárez VJ. Influence of psychological profile in autonomic response of nursing students in their first hospital clinical stays. Physiol Behav. 2019;207:99-103.

17. Diaz-Manzano M, Fuentes JP, Fernandez-Lucas J, AznarLain S, Clemente-Suárez VJ. Higher use of techniques studied and performance in melee combat produce a higher psychophysiological stress response. Stress Health. 2018;34(5):622-8.

18. Borg G. Perceived exertion as an indicator of somatic stress. Scand J Rehabil Med. 1970;2(2):92-8.

19. Krau SD. Summer activities: incidents and accidents. Crit Care Nurs Clin North Am. 2013;25(2):287-95. 
20. Stella AC, Vakkalanka JP, Holstege CP, Charlton NP. The epidemiology of caving fatalities in the United States. Wilderness Environ Med. 2015;26(3):436-7.

21. Badino G, Calaforra JM, Forti P, Garofalo P, Sanna L. The Naica caves and human physiology. In: Proceedings of the 15th International Congress of speleology. Kerrville, TX; 2009:1980-1984.

22. Bregani ER, Aliberti S, Guariglia A. Creatine combined with branched-chain amino acids supplement in speleological practice. A scientific controlled trial. Medicina Dello Sport. 2005;58(3):233-9.

23. Stenner E, Gianoli E, Biasioli B, Piccinini C, Delbello G, Bussani A. Muscular damage and intravascular haemolysis during an 18 hour subterranean exploration in a cave of 700 m depth. Br J Sports Med. 2006;40(3):235-8.

24. Pinna V, Magnani S, Sainas G, Ghiani G, Vanni S, Olla S, et al. Physical capacity and energy expenditure of cavers. Front Physiol. 2017;8:1067.

25. de la Cruz Torres B, Lopez Lopez C, Naranjo Orellana J. Analysis of heart rate variability at rest and during aerobic exercise: a study in healthy people and cardiac patients. $\mathrm{Br} J$ Sports Med. 2008;42(9):715-20.

26. Beltrán-Velasco AI, Ruisoto-Palomera P, Bellido-Esteban A, García-Mateos M, Clemente-Suárez VJ. Analysis of psychophysiological stress response in higher education students undergoing clinical practice evaluation. J Med Syst. 2019;43(3):68.

27. Belinchón-deMiguel P, Ruisoto-Palomera P, ClementeSuárez VJ. Psychophysiological stress response of a paralympic athlete during an ultra-endurance event. A case study. J Med Syst. 2019;43(3):70.

28. Clemente-Suarez VJ, Robles-Pérez JJ, Herrera-Mendoza K, Herrera-Tapias B, Fernández-Lucas J. Psychophysiological response and fine motor skills in high-altitude parachute jumps. High Alt Med Biol. 2017;18(4):392-9.

29. BBC News. The full story of Thailand's extraordinary cave rescue. Available at: https://www.bbc.com/news/world-asia44791998. Accessed July 14, 2019.

30. Clemente-Suárez VJ, Arroyo-Toledo JJ. The use of autonomic modulation device to control training performance after high-intensity interval training program. J Med Syst. 2018;42(3):47.

31. Hormeño-Holgado AJ, Clemente-Suárez VJ. Psychophysiological monitorization in a special operation selection course. J Med Syst. 2019;43(3):47.

32. Clemente-Suárez VJ. Psychophysiological response and energy balance during a 14-h ultraendurance mountain running event. Appl Physiol Nutr Metab. 2015;40(3):269-73.

33. Clemente-Suarez VJ. Changes in biochemical, strength, flexibility, and aerobic capacity parameters after a $1700 \mathrm{~km}$ ultraendurance cycling race. Biomed Res Int. 2014;2014: 602620.

34. Clemente-Suarez VJ, Palomera PR, Robles-Pérez JJ. Psychophysiological response to acute-high-stress combat situations in professional soldiers. Stress Health. 2018;34(2):247-52.

35. Sánchez-Molina J, Robles-Pérez JJ, Clemente-Suárez VJ. Psychophysiological and fine motor skill differences of elite and non-elite soldiers in an urban combat simulation. Mil Psychol. 2019;31(6):425-32.

36. Clemente-Suárez VJ, Robles-Pérez JJ. Psycho-physiological response of soldiers in urban combat. An Psychol. 2013;29(2):598-603.

37. Bellido A, Ruisoto P, Beltran-Velasco A, ClementeSuárez VJ. State of the art on the use of portable digital devices to assess stress in humans. J Med Syst. 2018;42(6): 100. 